\title{
Possible role of the Ec peptide of IGF-1Ec in cartilage repair
}

\author{
NIKOLAOS ARMAKOLAS ${ }^{1,2^{*}}$, ANDREAS DIMAKAKOS ${ }^{2 *}$, ATHANASIOS ARMAKOLAS $^{2^{*}}$, \\ ATHANASIOS ANTONOPOULOS ${ }^{1 *}$ and MICHAEL KOUTSILIERIS ${ }^{2 *}$ \\ ${ }^{1}$ Third Orthopaedic Clinic, KAT General Hospital, 14388 Athens; ${ }^{2}$ Physiology Laboratory, \\ Athens Medical School, National \& Kapodistrian University of Athens, 11527 Athens, Greece
}

Received June 18, 2015; Accepted March 22, 2016

DOI: $10.3892 / \mathrm{mmr} .2016 .5627$

\begin{abstract}
The Ec peptide (PEc) of insulin-like growth factor 1 Ec (IGF-1Ec) induces human mesenchymal stem cell (hMSC) mobilization and activates extracellular signal-regulated kinase $1 / 2$ (ERK 1/2) in various cells. The aim of the present study was to examine the effects of PEc on the mobilization and differentiation of hMSCs, as well as the possibility of its implementation in combination with transforming growth factor $\beta 1$ (TGF- $\beta 1$ ) for cartilage repair. The effects of the exogenous administration of PEc and TGF- $\beta 1$, alone and in combination, on hMSCs were assessed using a trypan blue assay, reverse transcription-quantitative polymerase chain reaction, western blot analysis, Alcian blue staining, wound healing assays and migration/invasion assays. It was determined that PEc is involved in the differentiation process of hMSCs towards hyaline cartilage. Treatment of hMSCs with either PEc, TGF- $\beta 1$ or both, demonstrated comparable cartilage matrix deposition. Furthermore, treatment with PEc in combination with TGF- $\beta 1$ was associated with a significant increase in hMSC mobilization when compared with treatment with TGF- $\beta 1$ or PEc alone $(\mathrm{P}<0.05)$. Thus, $\mathrm{PEc}$ appears to facilitate in vitro hMSC mobilization and differentiation towards chondrocytes, enhancing the role of TGF- $\beta 1$.
\end{abstract}

\section{Introduction}

Impairment of articular hyaline cartilage, can lead to different grades of disability depending on the functionality of the joint, and the grade of cartilage degeneration and destruction (arthritis). Acute trauma of a joint due to a sporting injury or accident, or chronic degeneration of the cartilage due to

Correspondence to: Professor Michael Koutsilieris, Physiology Laboratory, Athens Medical School, National \& Kapodistrian University of Athens, Mikras Asias 75, Building 16, Goudi, 11527 Athens, Greece

E-mail: mkoutsil@med.uoa.gr

*Contributed equally

Key words: insulin-like growth factor 1 Ec, Ec peptide, transforming growth factor- $\beta 1$, neo-chondrogenesis, mesenchymal stem cells, mobilization age, are the main and most frequent causes of severe impairment of articular cartilage that can lead to final stages of osteoarthritis and serious disability (1-3). The most common therapies [abrasion arthroplasty, autologous chondrocyte implantation (ACI), microfractures and arthroplasties] may not lead to complete rehabilitation and there is always the risk of side effects, such as infection of total arthroplasty and dislocation of the joint due to stem misorientation or loosening (1-5).

On these grounds, to avoid severe osteoarthritis and the requirement for arthroplasty surgery, research is being conducted in the field of neochondrogenesis $(2,5,6)$. Neochondrogenesis is a procedure during which the body is stimulated to form newly synthesized cartilage from mesenchymal stem cells (MSCs), at a specific location $(2,4)$. Several lines of evidence suggest that neochondrogenesis may become a promising alternative to prevent osteoarthritis. Studies on skeleton metabolism have led to the identification of a number of factors involved in cartilage formation by causing the differentiation of MSCs into chondrocytes (7-10). There are several approaches for administering these factors into the point of interest in laboratory animals and humans. It has been suggested that these factors can be administered directly into the point of interest (damaged cartilage) with rather encouraging results or in the form of a factor saturated scaffold $(11,12)$. In addition, in certain cases, apart from being saturated with growth factors, scaffolds contain premature chondrocytes obtained after the in vitro differentiation of autologous MSCs isolated from the patient (13-17).

One of the most potent factors that has been investigated for its ability to stimulate chondrogenesis in human MSCs (hMSCs) is transforming growth factor $\beta 1$ (TGF- $\beta 1$ ) (18). MSC transformation into chondrocytes in this case is stimulated though activation (phosphorylation) of extracellular signal-regulated kinase 1/2 (ERK 1/2) $(19,20)$.

Insulin-like growth factor 1 (IGF-1) is a potent growth and survival factor in human cancer, and the gene gives rise to multiple heterogeneous transcripts, IGF-1Ec among them, all resulting in the mature form of IGF-1. While the physiological role of IGF-1Ec is under debate, it has been known to participate in skeletal muscle repair, as well as in the cardiac remodeling/repair process $(21,22)$.

Recent evidence suggests that the Ec peptide (PEc), resulting from the proteolytic cleavage of the $\mathrm{COO}^{-}$terminal of the IGF-1Ec isoform, is associated with ERK 1/2 activation 
in various cell lines with adverse effects, including cellular proliferation, differentiation and satellite stem cell mobilization prior to repair (23-27). Also, there are indications that PEc participates in the healing process by affecting the expression pattern of osteogenic and adipogenic genes in MSCs, thus affecting differentiation during wound healing, while the mechanism by which it promotes proliferation and survival in cancer cells may in fact be mediated by a unique receptor $(28,29)$. Additionally, it has also been suggested that IGF-1Ec expression is stimulated by tissue damage leading to MSC attraction through PEc prior to repair, as was determined by in vitro assays (30).

The aim of the present study was to examine the effects of PEc on hMSCs and the possibility of increasing hyaline cartilage formation, using PEc in combination with TGF- $\beta 1$ to stimulate MSC migration (PEc) and differentiation (TGF- $\beta 1$ ) simultaneously.

\section{Materials and methods}

hMSC isolation. Human bone marrow was collected from the scrape material of three healthy donors aged 32, 37 and 29 years old, with open femur fractures. The material was used after all the patients filled in a written informed consent form. This study was approved by the institutional ethics committee and all experimental procedures conformed to the Declaration of Helsinki and was given and explained to the patients after the surgery and during their rehabilitation. The acquired marrow was briefly filtered through a $70-\mathrm{mm}$ mesh and the resulting cells were cultured at a density of $25 \times 10^{6}$ per $75-\mathrm{cm}^{2}$ flask in Dulbecco's modified Eagle's medium (DMEM) and 20\% fetal bovine serum (FBS; Gibco; Thermo Fisher Scientific, Inc. Waltham, MA, USA). The cells were incubated in a standard issue tissue culture incubator $\left(37^{\circ} \mathrm{C}\right.$ and $\left.5 \% \mathrm{CO}_{2}\right)$. The media was changed $3 \mathrm{~h}$ after initial culture and then every $8 \mathrm{~h}$ for the remaining $72 \mathrm{~h}$. The adherent cells were then trypsinized for 2 min at $25^{\circ} \mathrm{C}$ and examined for expression of the epithelial marker E-cadherin and the mesenchymal marker vimentin (Fig. 1A) (31).

Immunofluorescent staining. Cells cultured on culture slides (8-well, BD Biosciences, Franklin Lakes, NJ, USA) were stained by an indirect immunofluorescence method. Briefly, cells were rinsed in $1 \mathrm{X}$ phosphate-buffered saline (PBS) and fixed with ice-cold $80 \%$ methanol for $10 \mathrm{~min}$ at room temperature. They were permeabilized with $1 \mathrm{X}$ PBS plus $0.5 \%$ Triton $\mathrm{X}-100$ (Sigma-Aldrich, St. Louis, MO, USA) for $10 \mathrm{~min}$. They were then incubated with primary antibodies overnight at $4^{\circ} \mathrm{C}$ : Polyclonal rabbit anti-E-cadherin (1:100; ab15148; Abcam, Cambridge, UK) or monoclonal mouse anti-vimentin (1:100; ac8978330; Abcam, Cambridge, UK) in $1 \mathrm{X}$ PBS. After 3 washes with $1 \mathrm{X}$ PBS, each lasting $5 \mathrm{~min}$ at room temperature, cells were incubated for 30 min with goat anti-rabbit IgG conjugated to the fluorescent Alexa Fluor 488 dye (1:2,000, ab150077, Abcam, Cambridge, UK) or with goat anti-mouse IgG conjugated to the fluorescent Alexa 555 dye (1:2,000, A-21422, Thermo Fisher Scientific, Inc.) in $1 \mathrm{X}$ PBS. After 3 washes with $1 \mathrm{X}$ PBS, each lasting $5 \mathrm{~min}$ at room temperature, samples were stained with DAPI $(1 \mu \mathrm{g} / \mathrm{ml}$; Leica Microsystems, Inc., Buffalo Grove, IL, USA) for viewing with an Olympus BX40 microscope (Olympus, Tokyo, Japan).
Cell proliferation. For the Trypan Blue Exclusion assays, hMSCs were plated at a cell density of $3.5 \times 10^{4}$ cells/well in 6 -well plates and cultured in DMEM and 10\% FBS. After 24 and $48 \mathrm{~h}$ of culture, the cell number was counted using a hemocytometer (Celeromics Technologies, Cambridge, UK). A $0.4 \%$ solution of trypan blue in PBS was prepared and $0.1 \mathrm{ml}$ trypan blue solution was added to $1 \mathrm{ml}$ of cells. Immediately after, a hemocytometer was used to count the number of blue stained cells and the number of total cells. Blue staining cells are considered to be non-viable. Trypan blue exclusion assays determine the actual number of living cells.

Western blot analysis. Investigation of phosphorylated (p)-ERK 1/2 and total ERK 1/2 expression in the isolated hMSCs. TGF- $\beta 1$ (13 nM; Biognos, Waterven, Belgium) and PEc (17, 34 or 68 nM; Eastern Quebec Proteomic Core Facility, Sainte-Foy, Canada) were added in tissue culture wells with hMSCs at intervals of $0,0.5,1,2,4,24,48,72$ and $120 \mathrm{~h}$. Proteins were then isolated using radioimmunoprecipitation assay buffer with the addition of protease and phosphatase inhibitors (all Sigma-Aldrich). Western blot analysis was conducted after protein separation using $60 \mu \mathrm{g}$ sample loaded onto a $12 \%$ sodium dodecyl sulfate-polyacrylamide gel (Sigma-Aldrich). Proteins were transferred to polyvinlydene fluoride membranes and blocked in $0.1 \%$ milk in Tris-buffered saline. The membranes were incubated overnight at $4^{\circ} \mathrm{C}$ in the following primary antibodies: Rabbit anti-Phospho-p44/42 MAPK (Erk1/2) (Thr202/Tyr204) (1:2,000; 9101; Cell Signaling Technology, Inc., Beverly, MA, USA), and rabbit anti-p44/42 MAPK (Erk1/2) (1:2,000; 9102; Cell Signaling Technology, Inc.). Subsequently, membranes were incubated for $1 \mathrm{~h}$ at room temperature with horseradish peroxidase-conjugated goat anti-rabbit antibody (1:2,000; AP132P; EMD Millipore, Billerica, MA, USA). Detection was conducted using the Supersignal West Pico Chemiluminescent substrate (Thermo Fisher Scientific, Inc.).

Reverse transcription-quantitative polymerase chain reaction (RT-qPCR). The expression levels of Collagen (Col) I, Col II and Col X were assessed by RT-qPCR. RT-qPCR was performed in the Biorad IQ5 multicolor Real Time PCR detection system, using Sybergreen Supermix (Bio-Rad, Hercules, CA, USA). RNA extracts were obtained using TRIzol reagent (Thermo Fisher Scientific, Inc.). Each RT reaction was conducted using $1.5 \mathrm{mg}$ RNA mixed with $10 \mathrm{mmol} / \mathrm{l}$ dNTPs (New England Biolabs, Ipswich, MA, USA), $0.5 \mu \mathrm{g} / \mathrm{ml}$ oligo dTs (Thermo Fisher Scientific, Inc.) and $3 \mathrm{mg} / \mathrm{ml}$ random hexamer primers (Thermo Fisher Scientific, Inc.), it was heated at $65^{\circ} \mathrm{C}$ for 5 min and quick-chilled on ice. The RT Mix containing 200 U/ $\mu 1$ M-MuLV ProtoScript II Reverse Transcriptase, 5X ProtoScript II RT Reaction buffer, $0.1 \mathrm{~mol} / \mathrm{l}$ DTT and murine RNAse inhibitor (40 U/ $\mu \mathrm{l}$ ) (New England Biolabs) was then added, and the reactants were incubated at $42^{\circ} \mathrm{C}$ for $50 \mathrm{~min}$ and $70^{\circ} \mathrm{C}$ for $20 \mathrm{~min}$. Subsequently, each reaction was obtained in $20 \mu \mathrm{l}$ using $10 \mu \mathrm{l}$ KAPA SYBR FAST qPCR Master mix (Kapa Biosystems Inc., Wilmington, MA, USA), $2 \mu \mathrm{l}$ cDNA and $0.3 \mu \mathrm{mol} / 1$ primers $(23,24)$. The sequences for the primers used were as follows: Forward: 5'-AGGGCTCCAACGAGA TCGAGA-3' and reverse: 5'-AGGAAGCAGACAGGGCCA-3' for Col I; forward: 5'-CTATCTGGACGAAGCAGCTGG CA-3' and reverse: 5'-ATGGGTGCAATGTCAATGATGG-3' 

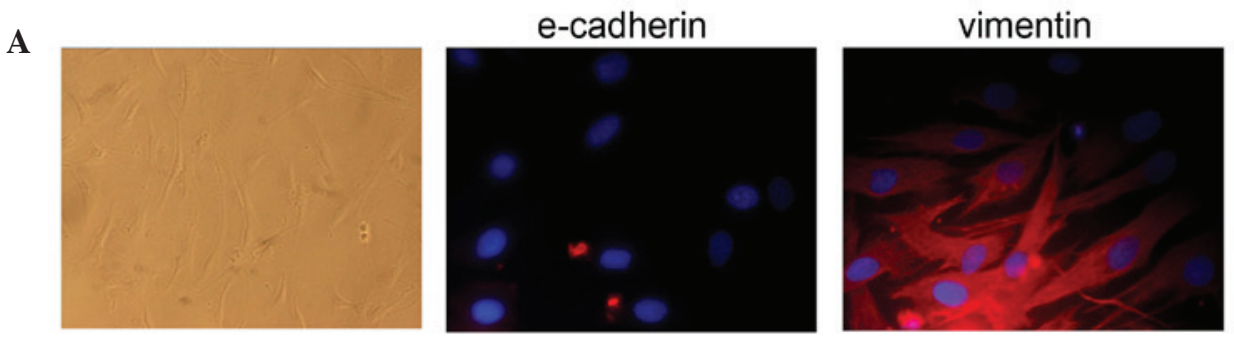

o $30 \min 60 \min 2 \mathrm{~h} \quad 4 \mathrm{~h} \quad 24 \mathrm{~h} \quad 48 \mathrm{~h} \quad 72 \mathrm{~h} \quad 120 \mathrm{~h}$

B

TGF- $\beta 1(13 \mathrm{nM})$

PERK 1/2

a

Total ERK $1 / 2$
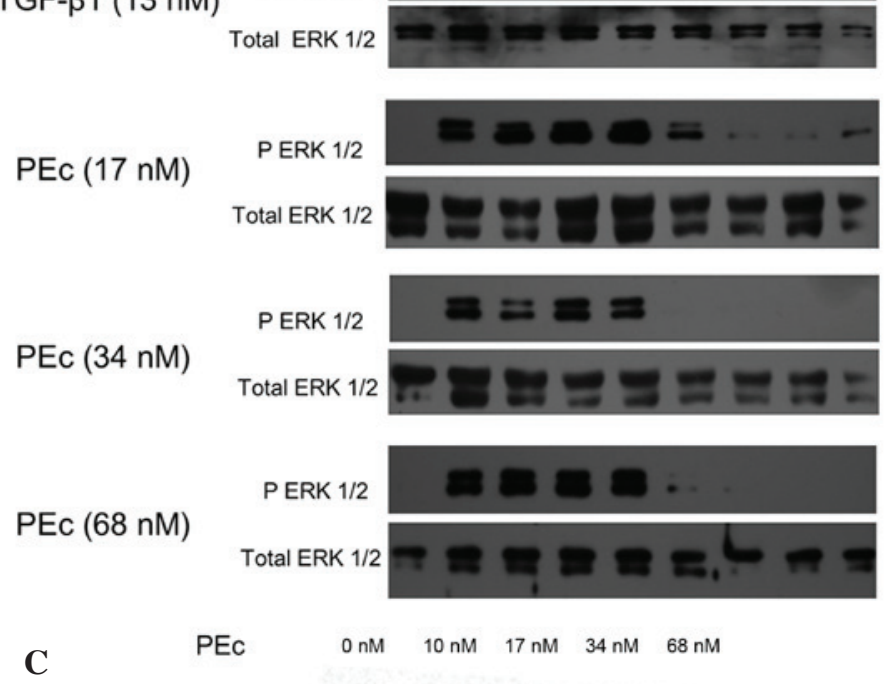

P ERK 1/2

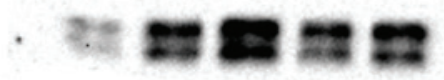

Total

ERK $1 / 2$

GAPDH

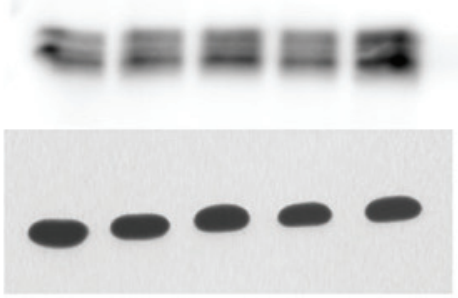

Figure 1. Effects of PEc on hMSC activation. (A) Characterization of the freshly isolated hMSCs by immunofluorescence (magnification, x200). The cells obtained from human bone marrow were examined for E-cadherin and Vimentin expression. It was determined that these cells were not expressing E-cadherin but were expressing vimentin at the protein level. In addition, the cellular morphology as was determined by light microscopy, was confirmatory to the mesenchymal nature of these cells. (B) The effect of different concentrations of PEc on hMSCs was examined by western blot analysis of ERK 1/2 phosphorylation, at different time intervals. It was determined that PEc activates ERK 1/2 whereas its optimum concentration (17 nM) was able to maintain the ERK $1 / 2$ phosphorylation for $24 \mathrm{~h}$, longer than that obtained with TGF- $\beta 1$ treatment $(4 \mathrm{~h})$. (C) The optimal PEc concentration $(17 \mathrm{nM})$ was determined by western blot analysis of ERK 1/2 phosphorylation at 30 min. hMSCs, human mesenchymal stem cells; PEc, Ec peptide; ERK, extracellular signal-regulated kinase; TGF- $\beta 1$, transforming growth factor- $\beta$; GAPDH, glyceraldehyde 3 -phosphate dehydrogenase.

for Col II; forward: 5'-GCTAAGGGTGAAAGGGGTTC-3' and reverse: 5'-CTCCAGGATCACCTTTTGGA-3' for Col $\mathrm{X}$; and forward: 5'-CCTCGCCTTTGCCGA-3' and reverse: 5'-TGGTGCCTGGGGCG-3' for $\beta$-actin (Eurofins Genomics GmbH, Ebersberg, Germany).

The PCR conditions were the same in all three cases: $95^{\circ} \mathrm{C}$ for $3 \mathrm{~min}$ for $1 \mathrm{cycle}, 94^{\circ} \mathrm{C}$ for $3 \mathrm{sec}$, then $60^{\circ} \mathrm{C}$ for $30 \mathrm{sec}$ for 40 cycles, and $70^{\circ} \mathrm{C}$ for $15 \mathrm{sec}$ for 50 cycles (increasing $0.5^{\circ} \mathrm{C}$ after every cycle) to determine the melt curve. Each reaction was performed in triplicate and values were normalized to $\beta$-actin. mRNA levels were quantified using iQ5 Optical System Software (Bio-Rad) and the $\Delta \Delta \mathrm{Cq}$ method (32).

Alcian blue. Cartilage matrix deposition in cells cultured in six-well dishes was quantified by Alcian blue staining. Cells were stained with Alcian blue (1\% in $3 \%$ acetic acid; Sigma-Aldrich) for $30 \mathrm{~min}$, washed three times for $2 \mathrm{~min}$ in $3 \%$ acetic acid, rinsed once with $1 \mathrm{X}$ PBS, and solubilized in $1 \%$ SDS. The staining was separately repeated without the final solubilization step. The absorbance at $605 \mathrm{~nm}$ was determined 
A

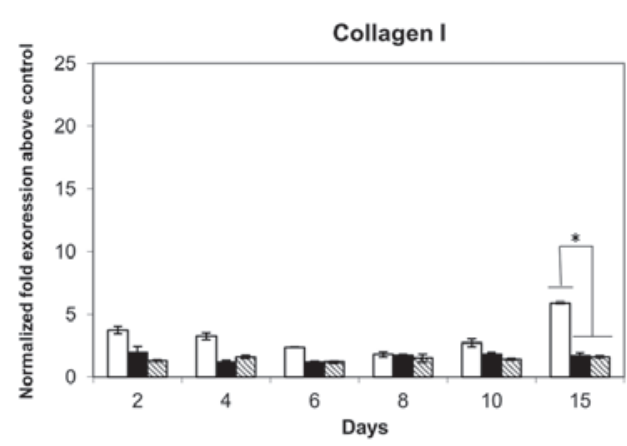

B

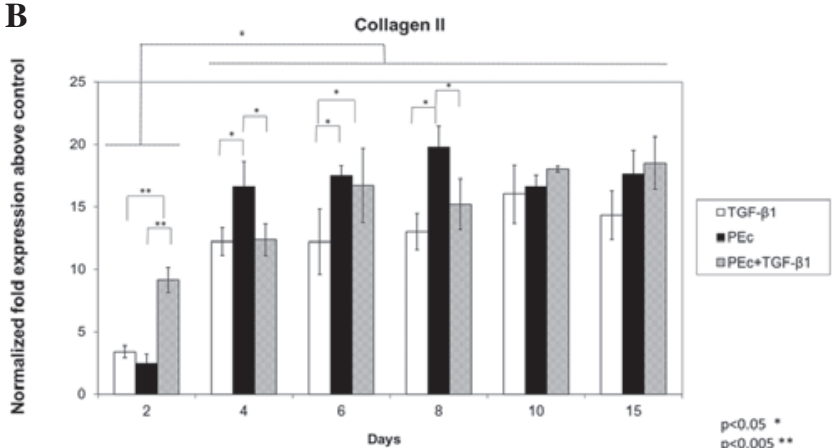

C

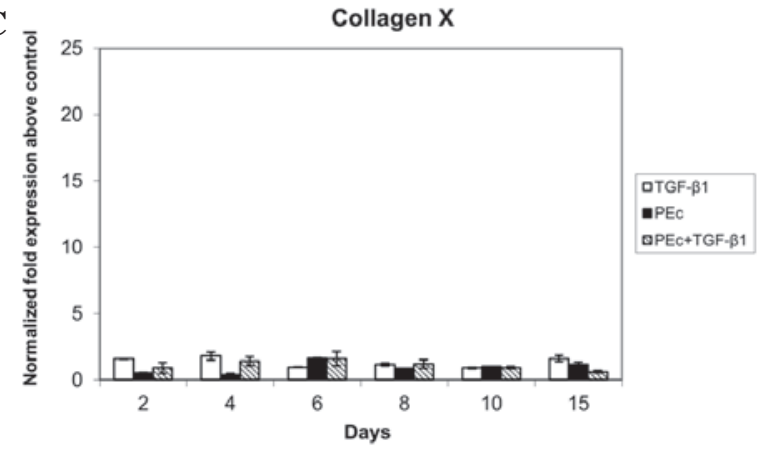

Figure 2. Quantitative analysis of the mRNA of Col I, Col II and Col X in hMSCs as assessed by reverse transcription-quantitative polymerase chain reaction, after the administration of TGF- $\beta 1, \mathrm{PEc}$ and the combination of both at different time points $(2,4,6,8,10$ and 15 days). (A) Administration of PEc (17 nM) and of PEc+TGF- $\beta 1$ lead to significantly lower expression of Col I compared with that obtained by TGF- $\beta 1$ treatment at day 15 (P<0.001). (B) PEc and $\mathrm{PEc}+\mathrm{TGF}-\beta 1$ administration were also associated with significant elevation of thew expression of Col II compared with that obtained by TGF- $\beta 1$ (P=0.002). (C) No significant difference was observed in any of the three treatments in respect to Col $\mathrm{X}$ expression. ${ }^{*} \mathrm{P}<0.05,{ }^{* *} \mathrm{P}<0.005$. hMSCs, human mesenchymal stem cells; Col, collagen; TGF- $\beta 1$, transforming growth factor $\beta 1$; PEc, Ec peptide.

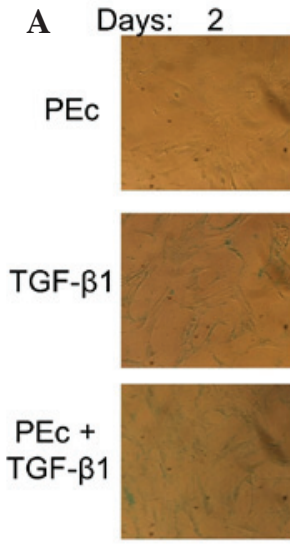

B
4
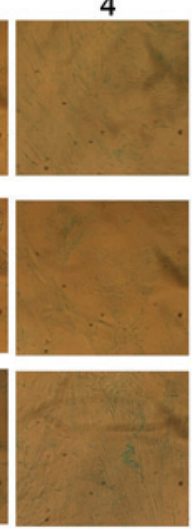

Time course of Alcian blue staining
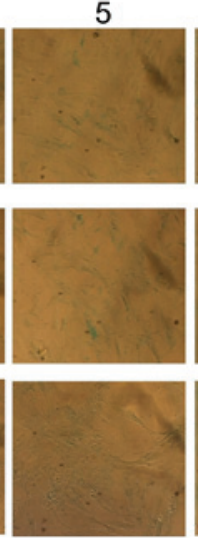

10
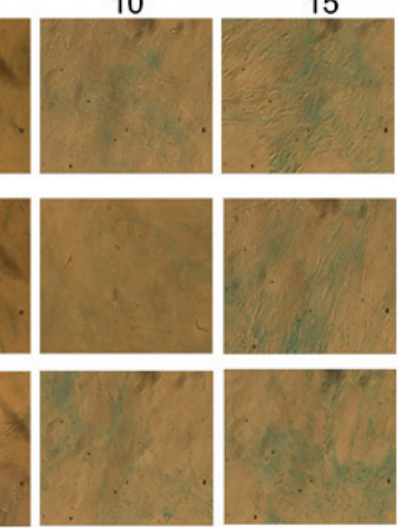

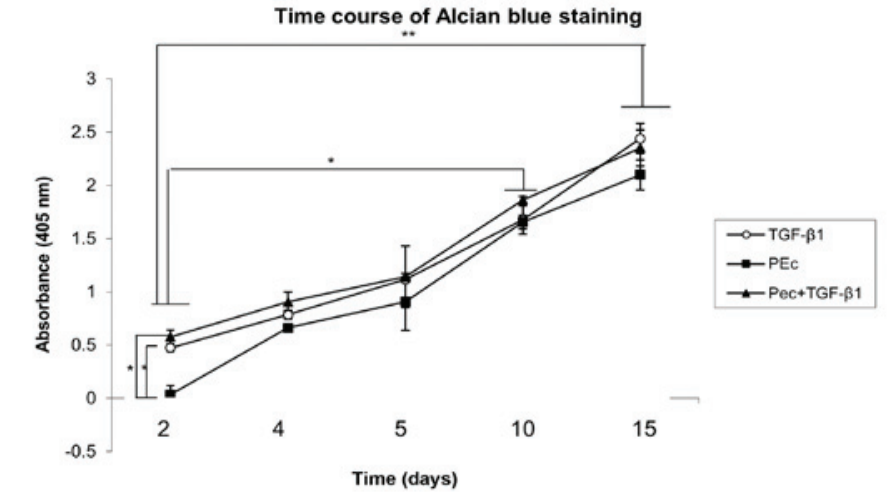

Figure 3. Alcian blue glycosaminoglycan staining and quantification in hMSCs treated with PEc, TGF- $\beta 1$ or with a combination of both, at different time intervals (2, 4, 5, 10 and 15) days. (A) All treatments resulted in a time-dependent increase in Alcian blue staining compared with the untreated hMSCs $(\mathrm{P}<0.001$ in every case). (B) No significant difference was observed in the Alcian blue staining caused by each of these factors when compared with each other. ${ }^{*} \mathrm{P}<0.05,{ }^{* *} \mathrm{P}<0.005$. hMSCs, human mesenchymal stem cells; TGF- $\beta 1$, transforming growth factor- $\beta$; PEc, Ec peptide. 
A
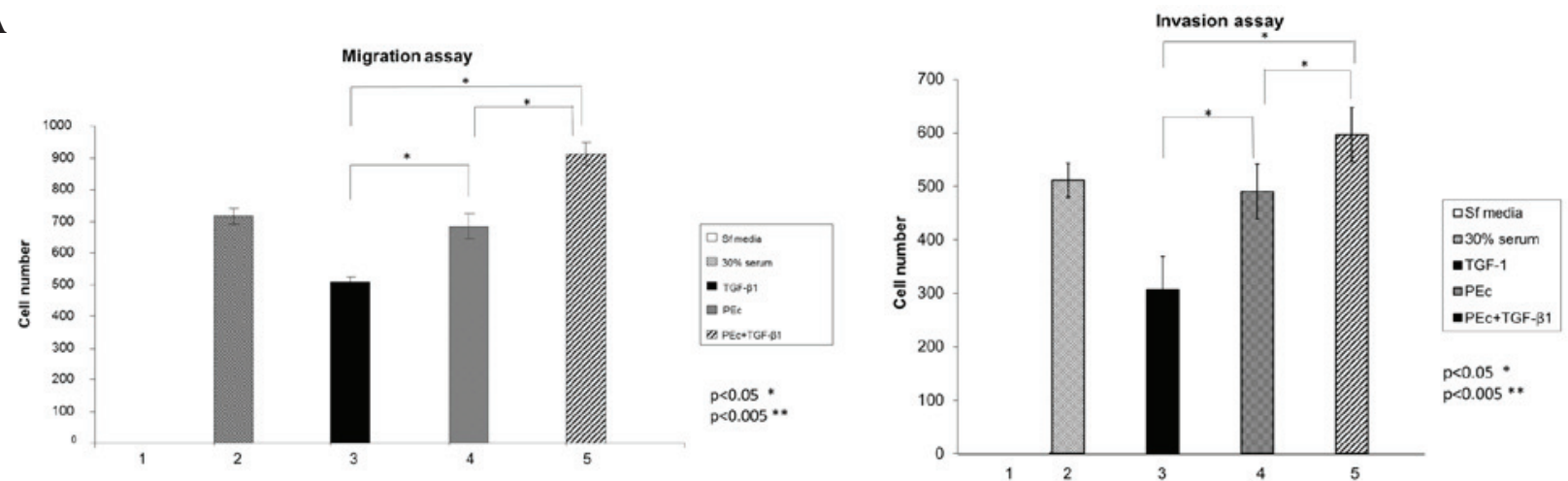
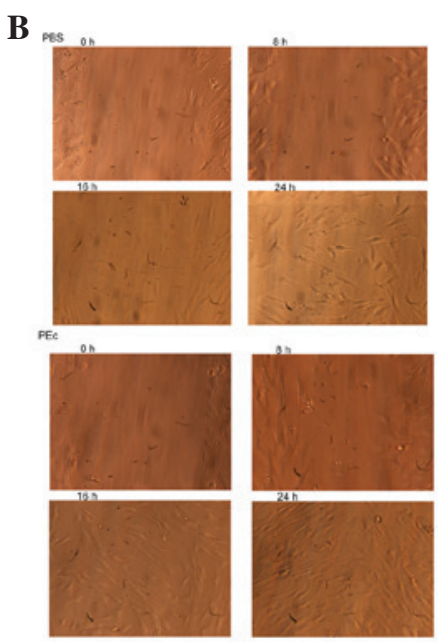
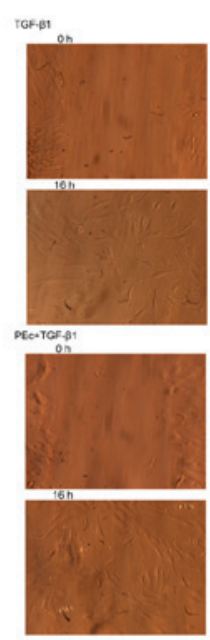
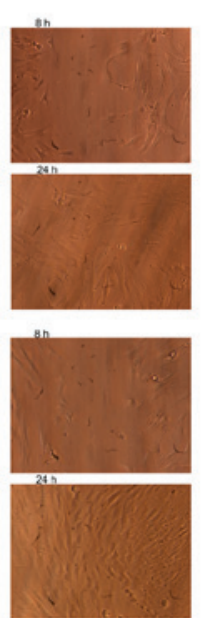

C Wound Healing assay

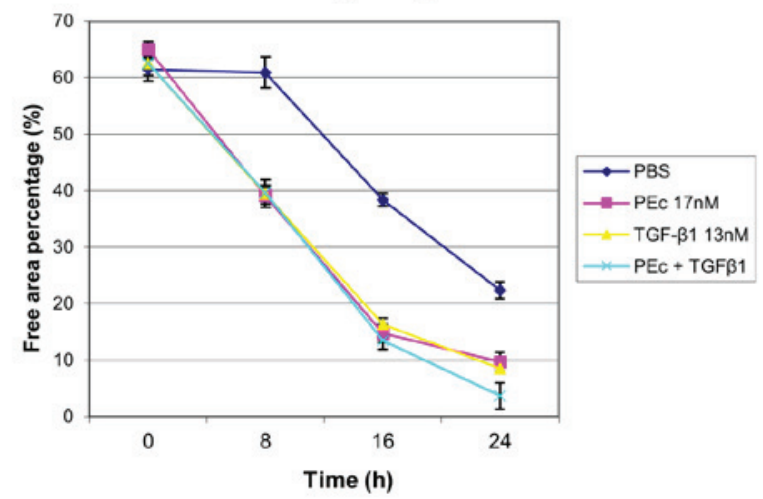

Figure 4. (A) Determination of the effects of PEc, TGF- $\beta 1$ and the combination of both, in the hMSC attraction as assessed by migration/invasion assays (Transwell system) at $24 \mathrm{~h}$. The top well always contained the hMSCs. PEc and PEc+TGF- $\beta 1$ were associated with a significant increase in hMSC migration and invasion compared with TGF- $\beta 1$ alone (migration assay PEc vs. TGF- $\beta 1$ : $\mathrm{P}=0.04$, PEc+TGF- $\beta 1$ : $\mathrm{P}<0.001$; invasion assay, $\mathrm{PEc}$ vs. TGF $\beta 1$ and $\mathrm{PEc}$ vs. PEc+TGF $\beta 1$ : $\mathrm{P}<0.002$ ). (B) Wound healing assay of the effects of PEc, TGF- $\beta 1$ and TGF- $\beta 1+P E c$ on the HMC mobilization. (C) Quantification of the wound healing assay. The combination treatment presented a significant increase in migration of hMSCs compared with the $\mathrm{PEc}$ alone $(\mathrm{P}=0.004)$. HMC treated with PEc in combination with TGF- $\beta 1$ presented a much greater mobilization activity in $24 \mathrm{~h}$ compared to the HMC treated with TGF- $\beta 1$ alone (one-way analysis of variance, $\mathrm{P}=0.008, \mathrm{n}=3)$. ${ }^{*} \mathrm{P}<0.05,{ }^{* *} \mathrm{P}<0.005$. PEc, Ec peptide; TGF- $\beta 1$, transforming growth factor $\beta 1$; hMSCs, human mesenchymal stem cells.

using a VersaMax microplate reader for triplicate samples (33) (Molecular Devices, LLC, Sunnyvale, CA, USA). To avoid random differentiation, the treatments were conducted in cells at $60-70 \%$ confluency.

Migration/invasion assay. Cell migration and invasion were analyzed using the Cultrex cell invasion assay (Trevigen Inc., Gaithersburg, MD, USA) according to the manufacturer's instructions. Briefly, for the invasion assay, the membrane in the upper chamber of the 96-well plate was coated with $0.5 \mathrm{X}$ basement membrane matrix/Matrigel. For the migration assay, the membrane was left uncoated. hMSCs were starved in serum-free medium for $8 \mathrm{~h}$ prior to the assay, then seeded at a density of $5 \times 10^{4}$ cells/well. After seeding $(24 \mathrm{~h})$, the cells on the lower surface were dissociated by aspiration and counted using a hemocytometer.

Wound healing assay. Isolated MSCs were cultured in DMEM supplemented with 10\% FBS and then seeded into 24-well tissue culture plate wells at a density of $4 \times 10^{6}$ cells/well, so that after $24 \mathrm{~h}$ of growth, they should reach $90-95 \%$ confluency as a monolayer. The monolayers were scratched with a sterilized $200 \mu$ l pipette tip vertically across the center of the well.
After scratching, the wells were washed twice with 1X PBS to remove the detached cells and replenished with fresh medium containing either TGF- $\beta 1$ (13 nM), PEc (17 nM) or TGF- $\beta 1$ $(13 \mathrm{nM})+\mathrm{PEc}(17 \mathrm{nM})$. Scratched monolayers replenished with just fresh medium were used as control samples. Images were collected at $0,8,16$, and 24 h using a Olympus BX40 microscope. Afterwards, the tscratch software, version 7.8 (Computational Science and Engineering Laboratory, Swiss Federal Institute of Technology, Zurich, Switzerland) was implemented in order to perform image analysis to measure the gap areas.

Statistical analysis. Changes in gene expression levels and cell numbers were assessed using one-way analysis of variance (SPSS v. 11 statistical package; SPSS Inc., Chicago, IL, USA). Where significant $F$ ratios were found $(P<0.05)$, the means were compared using Tukey's post-hoc tests. All data are presented as the mean \pm standard error of the mean. $\mathrm{P}<0.05$ was considered to indicate a statistically significant difference.

\section{Results}

Effect of PEc on MSC stimulation. Exogenous administration of the synthetic human PEc peptide stimulates the MSCs, as 
was determined by western blot analysis to determine the expression of p-ERK 1/2. This was also demonstrated for TGF- $\beta 1$. Further analysis prior to determining the optimum concentration of exogenous PEc, suggested that administration of $17 \mathrm{nM}$ PEc led to a prolonged phosphorylation time of ERK 1/2 compared with the higher concentrations used in this study (Fig. 1B).

Effect of PEc on MSC proliferation. Since PEc has previously been demonstrated to affect cellular proliferation in various cell lines, the effect of PEc on MSC proliferation was also examined. Exogenous administration of PEc on hMSCs was not associated with a significant increase in cell proliferation at any of the concentrations used (results not shown).

Expression of collagen. Since ERK 1/2 phosphorylation is associated with hMSC differentiation towards a chondrocytic fate, hMSCs treated with the optimum concentrations of PEc and with PEc+TGF- $\beta 1$ were examined for their expression of Col I, which is mainly expressed in tendons, ligaments and brittle cartilage, Col II that is the basis of articular and hyaline cartilage, and Col $\mathrm{X}$ that is expressed by hypertrophic chondrocytes during endochondral ossification (34). It was determined that the administration of PEc and PEc+TGF- $\beta 1$ were associated with a significantly lower expression of Col I at the 15th day compared with the effects of TGF- $\beta 1$ alone, and they presented similar levels of expression as the untreated hMSCs (Fig. 2A).

Col II expression was significantly higher in all the conditions examined compared with the untreated hMSCs, through the course of the study. Although PEc appears to be associated with a significant increase in Col II at days 4, 6 and 8 compared with the Col II levels obtained by TGF- $\beta 1$ and PEc+TGF- $\beta 1$ administration, at day 10 and 15 no significant difference was identified in the Col II expression stimulated by PEc, TGF- $\beta 1$ and PEc+TGF- $\beta 1$ treatments (Fig. $2 \mathrm{~B}$ ).

None of the factors examined were associated with a significant increase in $\mathrm{Col} \mathrm{X}$ through the course of the study (Fig. 2C).

Differentiation of hMSCs into a chondrocyte lineage. The stimulation of hMSCs towards chondrocytes was also examined by Alcian blue quantitation, where it was determined that PEc and PEc+TGF- $\beta 1$ presented similar levels of Alcian blue staining to that obtained by TGF- $\beta 1$ treatment alone, through the course of the study (15 days) (Fig. 3A and B). Spontaneous differentiation towards chondrocytes was examined in untreated hMSCs incubated in tissue culture conditions for 15 days. No significant transformation was observed of the untreated hMSC towards chondrocytes by Alcian blue staining after 15 days in tissue culture conditions (results not shown).

Recent evidence suggests that synthetic PEc can induce mesenchymal cell mobilization in vitro. Prior to that, the ability of PEc and of PEc in combination with TGF- $\beta 1$ to attract mesenchymal cells, was examined using a migration/invasion assay. PEc presented a significantly higher rate of mesenchymal cell migration and invasion capacity compared with TGF- $\beta 1(\mathrm{P}<0.05)$, and the combination of the two factors was associated with a significantly higher mesenchymal cell migration and invasion capacity than PEc alone (Fig. 4A).
To further examine the effect of these factors on hMSC mobilization, a wound healing assay was conducted. It was determined that hMSCs treated with PEc+TGF- $\beta 1$ exhibited a significantly elevated migration level at $24 \mathrm{~h}$ compared with TGF- $\beta 1$ or PEc alone, similar to that obtained by PEc treatment (Fig. 4B and C).

\section{Discussion}

MSCs are able to differentiate into osteoblasts, chondrocytes, and adipocytes and expand to numbers relevant for clinical application. Growth factors are essential in the chondrogenic differentiation of hMSCs. Previous studies have demonstrated that supplementation of TGF- $\beta 1$ initiated and improved chondrogenic differentiation of MSCs in a time- and dose-dependent manner (35).

In this study, the effects of PEc (the last 24 aa of the $\mathrm{COO}^{-}$ terminal of the IGF-1Ec isoform, not included in the mature IGF-1) on human mesenchymal cell differentiation and migration, alone and in combination with TGF- $\beta 1$ were examined. Recent evidence suggests that PEc attracts mesenchymal cells prior to the repair of myocardial cells and of muscle cells (26-28), whereas it was also found to inhibit HMSC osteogenic differentiation and induce differentiation towards adipocytes (28). TGF- $\beta 1$ is a known factior to cause HMSC cells to differentiate towards chondrocytes that has been introduced in clinical practise (12). The aim of the present study was to examine the possibility of using a combination of these factors in clinical practice. It was observed that PEc activates ERK $1 / 2$ in a similar manner to TGF- $\beta 1$. Since TGF- $\beta 1$ induces mesenchymal differentiation through ERK $1 / 2$ activation, the effect of PEc on mesenchymal cell differentiation was examined. The results obtained suggest that PEc, apart from inducing mesenchymal cell mobilization, interestingly and in contrast to a previous study (28), can also induce the differentiation towards chondrocytes, similar to TGF- $\beta 1$. The combination of both factors exhibited a greater effect as shown by significantly higher production of Col II and decreased production of Col I compared with the treatment with the two factors separately, whilst Col X was unaffected.

The effect of PEc, TGF- $\beta 1$, and the combination of both on the migration and invasion capacities of hMSCs was also investigated. PEc induced hMSC migration and invasion capacities more than TGF- $\beta 1$, whereas the combination of both factors was associated with a significant increase of the hMSC migration and invasion ability compared with PEc alone. The results from the wound healing assay were similar as it was determined that the combination of these two factors was associated with increased mesenchymal cell mobilization compared with TGF- $\beta 1$ alone and was similar to that induced by PEc.

These results suggest that the two factors do not negatively interfere with each other in respect to their effect on the differentiation and migration capacity of hMSCs into chondrocytes. The combination of these factors appears to have a synergistic effect in causing hMSC differentiation towards chondrocytes. Furthermore, the ability of PEc to attract hMSCs is not diminished when it is combined with TGF- $\beta 1$.

Further studies in in vivo models are required in order to better assess the effects of the introduction of PEc and of PEc together with TGF- $\beta 1$ on cartilage formation. 


\section{Acknowledgements}

This study was supported by the National and Kapodistrian University of Athens, as well as the Department of Physiology, Athens Medical School, Greece.

\section{References}

1. Clegg TE, Caborn D and Mauffrey C: Viscosupplementation with hyaluronic acid in the treatment for cartilage lesions: A review of current evidence and future directions. Eur J Orthop Surg Traumatol 23: 119-124, 2013.

2. Nicolini AP, Carvalho RT, Dragone B, Lenza M, Cohen M and Ferretti M: Updates in biological therapies for knee injuries: Full thickness cartilage defect. Curr Rev Musculoskelet Med 7: 256-262, 2014

3. Sofat N and Kuttapitiya A: Future directions for the management of pain in osteoarthritis. Int J Clin Rheumtol 9: 197-276, 2014.

4. Safran MR and Seiber K: The evidence for surgical repair of articular cartilage in the knee. J Am Acad Orthop Surg 18: 259-266, 2010.

5. Sterodimas A, de Faria J, Correa WE and Pitanguy I: Tissue engineering and auricular reconstruction: A review. J Plast Reconstr Aesthet Surg 62: 447-452, 2009.

6. Huckle J, Dootson G, Medcalf N, McTaggart S, Wright E, Carter A, Schreiber R, Kirby B, Dunkelman N, Stevenson S, et al: Differentiated chondrocytes for cartilage tissue engineering. Novartis Found Symp 249: 103-112; discussion 112-117, 170-174, 239-241, 2003.

7. Baghaban Eslaminejad M and Malakooty Poor E: Mesenchymal stem cells as a potent cell source for articular cartilage regeneration. World J Stem Cells 6: 344-354, 2014.

8. Florine EM, Miller RE, Porter RM, Evans CH, Kurz B and Grodzinsky AJ: Effects of dexamethasone on mesenchymal stromal cell chondrogenesis and aggrecanase activity: Comparison of agarose and self-assembling peptide scaffolds. Cartilage 4: 63-74, 2013.

9. Haleem-Smith H, Calderon R, Song Y, Tuan RS and Chen FH: Cartilage oligomeric matrix protein enhances matrix assembly during chondrogenesis of human mesenchymal stem cells. J Cell Biochem 113: 1245-1252, 2012.

10. Seo S and Na K: Mesenchymal stem cell-based tissue engineering for chondrogenesis. J Biomed Biotechnol 2011: 806891, 2011.

11. Bhardwaj N and Kundu SC: Chondrogenic differentiation of rat MSCs on porous scaffolds of silk fibroin/chitosan blends. Biomaterials 33: 2848-2857, 2012

12. Re'em T, Kaminer-Israeli Y, Ruvinov E and Cohen S: Chondrogenesis of hMSC in affinity-bound TGF-beta scaffolds. Biomaterials 33: 751-761, 2012.

13. Chen CC, Liao CH, Wang YH, Hsu YM, Huang SH, Chang CH and Fang HW: Cartilage fragments from osteoarthritic knee promote chondrogenesis of mesenchymal stem cells without exogenous growth factor induction. J Orthop Res 30: 393-400, 2012.

14. Lee JI, Sato M, Kim HW and Mochida J: Transplantatation of scaffold-free spheroids composed of synovium-derived cells and chondrocytes for the treatment of cartilage defects of the knee. Eur Cell Mater 22: 275-290; discussion 290, 2011.

15. Nakamura T, Sekiya I, Muneta T, Hatsushika D, Horie M, Tsuji K, Kawarasaki T, Watanabe A, Hishikawa S, Fujimoto Y, et al: Arthroscopic, histological and MRI analyses of cartilage repair after a minimally invasive method of transplantation of allogeneic synovial mesenchymal stromal cells into cartilage defects in pigs. Cytotherapy 14: 327-338, 2012.

16. Sato M, Uchida K, Nakajima H, Miyazaki T, Guerrero AR, Watanabe S, Roberts S and Baba H: Direct transplantation of mesenchymal stem cells into the knee joints of Hartley strain guinea pigs with spontaneous osteoarthritis. Arthritis Res Ther 14: R31, 2012.
17. Vanlauwe J, Huylebroek J, Van Der Bauwhede J, Saris D, Veeckman G, Bobic V, Victor J, Almqvist KF, Verdonk P, Fortems Y, et al: Clinical outcomes of characterized chondrocyte implantation. Cartilage 3: 173-180, 2012.

18. Tuli R, Tuli S, Nandi S, Huang X, Manner PA, Hozack WJ, Danielson KG, Hall DJ and Tuan RS: Transforming growth factor-beta-mediated chondrogenesis of human mesenchymal progenitor cells involves $\mathrm{N}$-cadherin and mitogen-activated protein kinase and Wnt signaling cross-talk. J Biol Chem 278: 41227-41236, 2003.

19. Li J, Zhao Z, Liu J, Huang N, Long D, Wang J, Li X and Liu Y: MEK/ERK and p38 MAPK regulate chondrogenesis of rat bone marrow mesenchymal stem cells through delicate interaction with TGF-beta1/Smads pathway. Cell Prolif 43: 333-343, 2010.

20. Zaslav K, McAdams T, Scopp J, Theosadakis J, Mahajan V and Gobbi A: New frontiers for cartilage repair and protection. Cartilage 3 (Suppl 1): S77-S86, 2012.

21. Achar RA, Silva TC, Achar E, Martines RB and Machado JL: Use of insulin-like growth factor in the healing of open wounds in diabetic and non-diabetic rats. Acta Cir Bras 29: 125-131, 2014.

22. Stavropoulou A, Halapas A, Sourla A, Philippou A, Papageorgiou E, Papalois A and Koutsilieris M: IGF-1 expression in infarcted myocardium and MGF E peptide actions in rat cardiomyocytes in vitro. Mol Med 15: 127-135, 2009.

23. Armakolas A, Philippou A, Panteleakou Z, Nezos A, Sourla A, Petraki C and Koutsilieris M: Preferential expression of IGF-1Ec (MGF) transcript in cancerous tissues of human prostate: Evidence for a novel and autonomous growth factor activity of MGF E peptide in human prostate cancer cells. Prostate 70: 1233-1242, 2010.

24. Philippou A, Armakolas A, Panteleakou Z, Pissimissis N, Nezos A, Theos A, Kaparelou M, Armakolas N, Pneumaticos SG and Koutsilieris M: IGF1Ec expression in MG-63 human osteoblast-like osteosarcoma cells. Anticancer Res 31: 4259-4265, 2011

25. Milingos DS, Philippou A, Armakolas A, Papageorgiou E, Sourla A, Protopapas A, Liapi A, Antsaklis A, Mastrominas M and Koutsilieris M: Insulinlike growth factor-1Ec (MGF) expression in eutopic and ectopic endometrium: Characterization of the MGF E-peptide actions in vitro. Mol Med 17: 21-28, 2011.

26. Wu J, Wu K, Lin F, Luo Q, Yang L, Shi Y, Song G and Sung KL: Mechano-growth factor induces migration of rat mesenchymal stem cells by altering its mechanical properties and activating ERK pathway. Biochem Biophys Res Commun 441: 202-207, 2013.

27. Hill M, Wernig A and Goldspink G: Muscle satellite (stem) cell activation during local tissue injury and repair. J Anat 203: 89-99, 2003.

28. Cui H, Yi Q, Feng J, Yang L and Tang L: Mechano growth factor E peptide regulates migration and differentiation of bone marrow mesenchymal stem cells. J Mol Endocrinol 52: 111-120, 2014.

29. Armakolas A, Kaparelou M, Dimakakos A, Papageorgiou E, Armakolas N, Antonopoulos A, Petraki C, Lekarakou M, Lelovas P, Stathaki M, et al: Oncogenic role of the Ec peptide of the IGF-1Ec isoform in prostate cancer. Mol Med 21: 167-179, 2015

30. Matheny RW Jr, Nindl BC and Adamo ML: Minireview: Mechano-growth factor: A putative product of IGF-I gene expression involved in tissue repair and regeneration. Endocrinology 151: 865-875, 2010.

31. Soleimani M and Nadri S: A protocol for isolation and culture of mesenchymal stem cells from mouse bone marrow. Nat Protoc 4 102-106, 2009.

32. Livak KJ and Schmittgen TD: Analysis of relative gene expression data using real-time quantitative PCR and the 2(-Delta Delta C(T)) Method. Methods 25: 402-408, 2001.

33. Lunstrum GP, Keene DR, Weksler NB, Cho YJ, Cornwall M and Horton WA: Chondrocyte differentiation in a rat mesenchymal cell line. J Histochem Cytochem 47: 1-6, 1999.

34. Pelttari K, Steck E and Richter W: The use of mesenchymal stem cells for chondrogenesis. Injury 39 (Suppl 1): S58-S65, 2008.

35. Pei M, He F and Vunjak-Novakovic G: Synovium-derived stem cell-based chondrogenesis. Differentiation 76: 1044-1056, 2008. 